\title{
A CIRCULARIDADE VIRTUOSA: INVESTIGAÇÃO SOBRE DUAS ESCOLAS NO RIO DE JANEIRO
}

\author{
ZAIA BRANDÃO \\ Programa de Pós-Graduação em Educação da \\ Pontifícia Universidade Católica do Rio de Janeiro \\ zaia@edu.puc-rio.br \\ DIANA MANDELERT \\ Programa de Pós-Graduação em Educação da \\ Pontifícia Universidade Católica do Rio de Janeiro \\ mandelert@brfree.com.br

\section{LUCÍLIA DE PAULA} \\ Programa de Pós-Graduação em Educação da \\ Pontifícia Universidade Católica do Rio de Janeiro \\ lucilia@dorio.com.br
}

\section{RESUMO}

Este trabalho sistematiza resultados preliminares de um programa de pesquisa do Grupo de Pesquisas em Sociología da Educação da Pontifícia Universidade Católica do Rio de Janeiro Soced/PUC-Rio - sobre as características dos jovens de $8^{a}$ série (faixa de 13/14 anos) que freqüentam duas das escolas privadas de prestígio na cidade do Rio de Janeiro. Trata-se de recorte do material desse programa, que visa à análise das características institucionais e familiares que interagem no processo de escolarização desses jovens, produzindo a imagem de excelência escolar em que se ancora o prestígio adquirido por essas escolas.

ESCOLAS - RIO DE JANEIRO - QUALIDADE DO ENSINO - PESQUISA

\begin{abstract}
VIRTUOUS CIRCULARITY - AN INVESTIGATION ON TWO SCHOOLS IN RIO DE JANEIRO. This paper systematizes the preliminary results of a research program conducted by the Research Group on Sociology of Education of Rio de Janeiro Catholic University Soced/PUC-Rio - on the characteristics of $8^{\text {th }}$ graders (the 13-14 age group) attending two renowned private schools in Rio de Janeiro. It deals with an aspect of the corpus of this research that addresses institutional and familial characteristics that interact in the learning process of these youngsters in order to produce an image of teaching excellence whereupon the prestige acquired by such schools rests.

SCHOOLS - RIO DE JANEIRO - TEACHING QUALITY - RESEARCH
\end{abstract}


Este trabalho sistematiza resultados preliminares sobre as características dos jovens de $8^{a}$ séries (faixa de 13// 4 anos) que freqüentam duas das escolas de prestígio na cidade do Rio de Janeiro. Trata-se de um recorte do material de um programa de pesquisa' desenvolvido pelo Soced/PUC-Rio: "Processos de produção de qualidade de ensino: escola, família e cultura". Essa investigação visa a análise das características institucionais e familiares que interagem no processo de escolarização desses jovens, produzindo a imagem de excelência escolar em que se ancora o prestígio adquirido por tais escolas, baseado principalmente no desenvolvimento dos egressos nos exames de vestibular para os cursos e universidades mais procurados.

Em um primeiro momento, e em caráter exploratório, entrevistamos duas mães, uma professora e desenvolvemos um trabalho de campo com observações no ambiente escolar e, principalmente, em salas de aula. Com base nessas observações desenvolvemos um survey, composto de três questionários, que nos permitiriam traçar um perfil sociodemográfico dos principais agentes educativos dessas escolas (alunos, pais e professores) que repercutem direta ou indiretamente nos processos de escolarização dos jovens. Este texto faz uma primeira interpretação do material produzido.

As duas escolas, situadas em um mesmo bairro residencial de camadas médias e altas, figuram no ápice do ranking - divulgado na imprensa - das meIhores instituições educativas do Rio de Janeiro: uma escola tradicional confessional, de orientação católica, e outra bilíngüe. A primeira com cerca de três mil alunos e a segunda com aproximadamente mil.

O questionário dos alunos foi aplicado em sala de aula em um total de 319 alunos. O dos pais foi encaminhado pelos alunos e tivemos o retorno de 137 sujeitos; 29 professores das $8^{\text {as }}$ séries responderam o questionário

As informações obtidas pelos questionários, aliadas às observações e entrevistas exploratórias, permitem esboçar um quadro das características do investimento dessas famílias na escolarização dos filhos, a relação dos jovens com o estudo, assim como construir alguns indicadores do trabalho pedagógico e do clima da escola.

I. Este programa investiga os processos de escolarização das elites cariocas. Uma primeira pesquisa focalizou a escolarização de filhos das elites acadêmicas (Brandão, Lelis, 2003). Atualmente a pesquisa focaliza seis escolas de grande prestígio no Rio de Janeiro utilizando como principal instrumento um survey composto de três questionários: alunos, pais e professores. 


\section{O “MUNDO NATAL” E AS TRAJETÓRIAS ESCOLARES}

Bourdieu (1999) utiliza a expressão "mundo natal" para referir-se ao ambiente de socialização primária. Afirma que este se impõe a todo o momento por ser "o mundo maternal, aquele dos gostos primordiais..." e que reflete na verdade as "relações sociais objetivadas nos objetos familiares", como por exemplo, na decoração da casa, nas roupas, nos gostos e, como apurado na pesquisa, na posse e consumo de bens culturais.

Os jovens estudados são em sua maioria oriundos de famílias nucleares, compostas pelos pais e dois filhos, sendo que a dissolução do vínculo conjugal atinge apenas uma minoria das famílias investigadas. Refletindo uma tradição social brasileira, quando ocorre separação os filhos normalmente ficam sob a guarda materna. Assim, $96 \%$ dos alunos ${ }^{2}$ de ambos os colégios afirmam residir com a mãe, sendo que destes, a maioria (77\%) reside com pai e mãe. Um percentual de $18 \%$ dos alunos são filhos únicos. As famílias numerosas são minoritárias, sendo que a proporção de famílias com três ou mais filhos é maior ( I5\%) no colégio bilíngüe do que no colégio confessional (8\%). Dominam, portanto as famílias com dois filhos (52\%) às quais somadas as de $18 \%$ de fiIhos únicos representam $70 \%$ das situações, confirmando a presença de uma estratégia de redução da prole freqüente entre as camadas médias e médias altas, o que possibilita investimentos mais elevados na educação das novas gerações ${ }^{3}$.

De um modo geral, os alunos investigados percebem seus pais presentes no cotidiano: 70\% afirmam quase sempre almoçar ou jantar com eles, e 27\% o fazem algumas vezes. Quanto ao tema das conversações com os pais, apuramos que $58 \%$ deles conversam sobre livros, filmes ou TV, freqüentemente, e 38\% algumas vezes; as conversas sobre assuntos políticos, embora presentes no cotidiano familiar, são muito menos constantes ${ }^{4} .49 \%$ dos jovens afirmam quase sempre realizar programas comuns com os pais sendo que $47 \%$ o fazem eventualmente.

2. Todos os percentuais foram arredondados.

3. Bourdieu (1998, p.99) explica que a redução da prole relaciona-se com o investimento na escolaridade dos filhos, ampliando as chances de ascensão social objetivamente oferecidas aos membros das diferentes classes ou frações de classes.

4. Essa certamente é uma situação conjuntural, pois o questionário foi aplicado mais de um mês após as eleições presidenciais, portanto em uma fase de recesso dos debates políticos. 
Tais dados indicam a presença de um forte vínculo socioafetivo-familiar, de grande importância para a transmissão e ampliação da estrutura e volume de capitais acumulados pela família. Esse convívio cotidiano, marcado por situações de proximidade física adensa as trocas simbólicas e materiais entre as duas gerações, proporciona o gosto por atividades comuns e a freqüência a determinados campos no espaço social, que reforçam as condições de transmissão da herança cultural e a constituição do habitus de classe entre os jovens.

Esse estilo de vida familiar de maior proximidade entre as gerações aponta no sentido contrário do que as mídias têm indicado sobre a "desestruturação das famílias" e a ausência de diálogo familiar; também pode ser um reflexo da faixa etária dos jovens estudados que, em vista do contexto social de maior violência característico das metrópoles, têm sua liberdade de ir e vir bastante limitada. Os jovens estudados encontram-se no limite da clivagem etária que permitirá maior autonomia no que concerne a opções de saída e lazer.

Em relação ao apoio familiar à escolaridade ${ }^{5}$, há fortes indicadores de uma relação de parceria com os pais, que se expressa em uma forma de lidar com as atividades e exigências escolares adequada à construção da autonomia dos estudantes. Evidenciando essa parceria, constatamos que $66 \%$ dos pais estão presentes quando o filho pede ajuda e acompanham sua vida escolar. Observamos, porém, algumas variações nas famílias pesquisadas em relação à construção da autonomia desses jovens: um grupo de pais (26\%) indicou fazer um acompanhamento constante e irrestrito das tarefas escolares, mesmo quando os filhos não demandam ajuda; essa postura é assinalada nos questionários dos filhos, com a informação que $50 \%$ dos pais conversam quase sempre sobre seu rendimento escolar; outros pais (6\%) afirmam, diferentemente, que deixam seus filhos inteiramente responsáveis pelas tarefas escolares, informação essa reiterada por $6 \%$ dos filhos que declaram nunca conversar sobre rendimento escolar com os pais. Perguntados sobre o porquê do recurso a professores particulares (38\% dos alunos informaram recorrer a aulas particulares) a maioria dos alunos (82\%) assinalou "porque achei necessário", e apenas I 5\% "porque meus pais julgaram necessário". Tal atitude é reiterada pelas respostas negati-

5. Coleman (1988) desenvolveu o conceito de capital social para representar a rede de apoio mobilizada pela família à educação dos filhos. Na perspectiva de Bourdieu, por nós adotada, este apoio decorre da própria estrutura do capital cultural (escolar, informacional, literário...) da família. 
vas às perguntas: "se faziam as tarefas de casa porque os pais obrigam" (93\%), e "se faziam os trabalhos escolares porque valiam notas" (74\%). Esses alunos demonstram responder positivamente às demandas escolares sem depender de uma pressão exterior, provavelmente por terem adquirido uma autodisciplina fruto da internalização da importância dessas tarefas para seu bom desempenho escolar. Se a esses dados acrescentarmos a reação da maioria dos pais (80\%) de apoiar os estudos do filho quando seu desempenho é baixo, temos indicadores da predominância de um estilo educativo das famílias dirigido à construção da autonomia dos estudantes (promovendo a auto-avaliação). Esse estilo afasta-se das práticas heterônomas ${ }^{6}$ mais comuns entre as famílias de baixa escolarização, como impor sanções, questionar a escola ou oferecer incentivos materiais, pouco assinaladas entre os nossos respondentes.

Nogueira (2000, p. I 4 I ) aponta que a atitude autodisciplinada dos estudantes constitui um "treinamento para a excelência e autonomia intelectual, para a formação de um 'espírito crítico', valor intelectual contemporâneo cuja rentabilidade no mercado escolar nem sempre é imediata ou facilmente visível". Essa atitude se diferencia daquela em que o estudo ocorre meramente como resultado de sanção exterior (nota, aprovação, diploma). A presença e a participação dos pais na vida escolar desses jovens destaca-se, portanto, como um diferencial, em relação a outros estratos sociais, que irá marcar os processos de construção da qualidade de ensino nessas escolas. Tais processos pressupõem a parceria das famílias no desenvolvimento de estratégias educativas que garantam, no plano simbólico e material, o desenvolvimento de práticas e representações adequadas a uma escolarização bem-sucedida, ou seja, um mundo natal consistente com os padrões de exigência das escolas de maior prestígio no Rio de Janeiro. A relação entre as estratégias das famílias e a lógica das instituições escolares permite, segundo Bourdieu (1 996, p.35), a reprodução do capital escolar.

Ao analisarmos os dados dos questionários referentes à trajetória escolar desses jovens, constatamos que $96 \%$ nunca estudaram em escolas públicas $^{7}$. Sabemos ainda que 44\% nunca mudaram de escola e $90 \%$ nunca tive-

6. Lahire (1997, p.95) classifica como práticas heterônomas (dependentes do exterior) as que implicam uma disciplina, que tem como fonte os pais ou adultos, exercida sempre de fora sobre o indivíduo.

7. Apenas $1 \%$ estudou anteriormente só em escola pública e os $3 \%$ restantes tiveram uma trajetória mista (pública/particular). 
ram repetência escolar. Essa escolaridade sem rupturas - tão comum entre estudantes que freqüentam as escolas de prestígio - é fruto das estratégias conjugadas família/escola. Em entrevistas com os diretores, pudemos perceber que a reprovação raramente é aceita por essas escolas. Quando um aluno reprovado é autorizado a matricular-se na mesma série, fato excepcional na escola confessional, o faz na condição de obter médias que indiquem um desempenho sem risco de reincidir no fracasso, ainda no primeiro semestre, mediante um termo de compromisso com a instituição. Caso não tenha um desempenho adequado ao compromisso assumido, o aluno deve procurar outra escola. No que toca à escola bilíngüe, o acompanhamento é permanente, e os pais são convocados ao primeiro sinal de dificuldades que possa comprometer o fluxo normal do processo escolar como é o caso de dificuldades no domínio da língua estrangeira, verificou-se por sinal, que a maior parte das aulas particulares eram de apoio à língua estrangeira. Essas estratégias família/ escola apontam que, quando necessário, são acionadas alternativas que mascaram o fracasso escolar, tais como: transferência de escola, apoio de professores particulares, terapias etc.

O monitoramento da escolaridade desses jovens, tanto por parte dos pais como das escolas, tem repercussões importantes sobre o autoconceito dos alunos que, na lógica do efeito pigmaleão ${ }^{8}$, tendem a se tornar o que deles se espera: bons estudantes. Na auto-avaliação das notas em relação às da turma, apenas $16 \%$ dos alunos localizaram-se abaixo da média. Praticamente um terço do grupo (29\%) afirma-se acima da média e 54\% na média.

$\mathrm{Na}$ questão sobre o tempo dedicado ao estudo, a indicação de que $50 \%$ estudam entre uma a três horas por semana soa, à primeira vista, como pouco estudo para escolas que tendem a se destacar pelo nível de exigência. Entretanto, é preciso levar em conta que esse percentual pode estar subestimado, pois quando perguntados se estudam nos finais de semana, 66\% afirmaram fazê-lo algumas vezes, e $16 \%$ indicaram fazê-lo quase sempre, o que evidenciaria a prática, muito comum entre jovens, de estudar intensamente às vésperas de provas e testes. Esse tempo, possivelmente, nem sempre foi computado pelos jovens no cálculo da média semanal. Se acrescentarmos a esse

8. Rosenthal e Jacobson (1968) relatam as pesquisas em que se basearam para desenvolver a self-fullfilling profhecy, ou seja, as expectativas dos professores em relação às competências de seus alunos que tendem a se realizar. 
resultado relativo a média indicada por $40 \%$ dos alunos (31\% estudam de três a cinco horas por semana, $4 \%$ entre cinco e oito horas e $5 \%$ mais de oito horas semanais), percebemos que para esses, considerando sua faixa etária (plena puberdade e adolescência), a carga de estudo é bem elevada.

Acresça-se a isso, o fato de $65 \%$ dos pais possuírem o curso superior e $28 \%$, pós-graduação stricto sensu, o que significa que esses jovens estão imersos em um mundo natal em que as atividades intelectuais seguem a norma típica dos ambientes de capital cultural elevado. Os alunos dispõem de um sem número de recursos paraescolares (enciclopédias, CD-roms educativos), do acesso desde a mais tenra idade à internet, com domínio das ferramentas de busca, além de bibliotecas em casa, contendo obras variadas (literatura, história, livros técnicos, arte etc.). Some-se a este capital cultural objetivado ${ }^{9}$ as temáticas das conversas às refeições, o capital informacional que circula cotidianamente na casa pelo hábito diário (dos pais) de leitura de jornais e revistas informativas (96\%), assim como pela prática de assistir aos noticiários televisivos (97\%).

\section{O PROCESSO DE INTERNACIONALIZAÇÃO DAS ELITES}

O domínio de línguas estrangeiras tem-se revelado, cada vez mais, uma característica básica da educação dos segmentos das elites e uma estratégia de distinção, confirmado por $79 \%$ dos alunos que afirmam ter bom conhecimento de inglês, sendo desprezível ( $1 \%$ ) o percentual dos que assinalaram ter fraco ou nulo conhecimento. Em relação aos demais idiomas, a freqüência dos que assinalam ter conhecimento fraco ou nulo é de $85 \%$ para francês e $63 \%$ para espanhol.

O estudo de um outro idioma estrangeiro teve uma freqüência alta devido aos alunos da escola bilíngüe (6 I \%). Há uma diferença entre as duas escolas, em relação aos cursos extracurriculares de línguas estrangeiras: apenas $26 \%$ dos alunos da escola bilíngüe freqüentam-nos enquanto na escola confessional o percentual é de $87 \%$. Provavelmente o fato de a escola bilíngüe já garantir o aprendizado de um outro idioma, que não o inglês, justifica essa situação. Atualmente é crescente o número de alunos brasileiros nos colégios bilíngües - em dois colégios bilíngües investigados cerca de $80 \%$ dos estudan-

9. Para Bourdieu (2003, p.77) o capital cultural objetivado refere-se aos suportes materiais, transmitidos em sua materialidade, como objetos e instrumentos, livros, obras de arte etc. 
tes são compostos por filhos de brasileiros -, situação muito diferente da que ocorria há uma década, o que se configura em um indicador do processo de internacionalização dessas frações de elite.

Além do estudo e domínio da língua estrangeira, outro indicador da internacionalização está na freqüência das viagens internacionais nos últimos três anos. Permanece um diferencial entre as duas escolas: viajaram para o exterior: $87 \%$ dos alunos da escola bilíngüe, e $60 \%$ da escola confessional. Notamos ainda uma evidente preferência pela Europa (79\%) como destino das viagens realizadas por alunos da escola bilíngüe, em relação aos EUA e o Canadá (26\%), provavelmente devido à origem européia da escola. O contrário ocorre com o colégio confessional, que prefere os EUA e ao Canadá (47\%) em relação à Europa (16\%), que ocupa o terceiro lugar na escolha do destino.

As viagens para a América Latina e o Caribe têm uma freqüência de apenas $18 \%$ apesar do custo menor. Essa atitude reflete um padrão cultural vigente no país, que confirma o pequeno interesse pela cultura latino-americana, e pela língua espanhola, entre esses segmentos. Da mesma forma, a língua espanhola, apesar de sua crescente importância no panorama internacional, não aparece com destaque entre os investimentos de aprendizagem extracurriculares dos jovens estudados. Lamentavelmente, apesar de o Brasil integrar sociogeograficamente a América Latina, o país está mais próximo do hemisfério norte no imaginário cultural das elites.

Uma outra dimensão relevante na caracterização das práticas culturais dessas frações de elite é o uso de novas tecnologias de informação. Esses jovens, integrantes de uma minoria ricamente informada, dispõem de padrões e comportamentos de consumo e entretenimento com conseqüências importantes sobre os gostos e padrões de consumo. O acúmulo de capital informacional (Dantas, 2002) funciona como uma dimensão da estrutura do capital cultural, alterando as formas de vida dos grupos e das famílias. Nossos dados permitem identificar um acúmulo evidente de capital informacional, condizente com o perfil desse estrato social. Cerca de $83 \%$ dos alunos lêem jornais e mais de $35 \%$ realizam a leitura semanal de revistas informativas.

Constatamos, ainda em relação aos hábitos de leitura dos alunos, que 85\% utilizam a internet com freqüência, ou seja, desenvolvem uma prática de leitura (e-mails e sites) cada vez mais disseminada entre os jovens brasileiros das frações estudadas. Os dados do Programa Internacional de Acompanhamento das Aquisições dos Alunos - PISA - mostram que o Brasil está longe de 
ter a habilidade em leitura de forma suficiente. Comparando os nossos alunos de nível socioeconômico e cultural elevado com os de outros países, o Brasil ficou em último lugar, ao lado do México (Franco, 2002). Quanto às leituras ${ }^{10}$, apuramos que esses jovens preferem as obras de ficção, seguidas pelos livros de não ficção". Quando solicitados que citassem os livros de que mais gostaram nos últimos dois anos, os dados evidenciam uma prática de leitura pouco comum entre os jovens brasileiros dessa faixa etária ${ }^{12} .5 \%$ dos alunos citaram apenas um livro, $11 \%$ citaram dois livros e $81 \%$ mais de três livros. Note-se que apenas $1,5 \%$ dos alunos afirmou não ter lido nenhum livro nos últimos dois anos. Cabe destacar que embora 30\% dos alunos afirmassem ler apenas o necessário, 13\% apontaram sua dificuldade de ler livros até o fim, e 7\% acharam ler uma perda de tempo. Entretanto, 24\% afirmaram ter na leitura uma das suas diversões preferidas e $30 \%$ gostam muito de ir a livrarias.

Os dois últimos dados, se confrontados com os baixos níveis de escolaridade no Brasil, comprovam o diferencial desses jovens no plano cultural.

Entre as atividades culturais preferidas pela maioria dos jovens investigados, destaca-se o cinema (99\%), seguida, na ordem de preferência, pelos eventos esportivos (69\%). O teatro e os shows de música popular são freqüentados por 65\% dos alunos. A prática de esportes, na proporção de 63\% dos alunos, está consistente com um estilo de educação familiar que tem como valor fundamental a saúde física e a estética corporal dos filhos.

Nossos dados ilustram a baixa de freqüência a espaços públicos relacionados à oferta cultural clássica ${ }^{13}$ (museus, salas de teatro e música erudita). Essa

10. Os dados: $51 \%$ nunca lêem poesia, e apenas cerca de $8 \%$ o fazem quase sempre. As obras de ficção são lidas quase sempre por cerca de 34\% dos alunos, sendo que 19\% assinalaram que nunca lêem ficção.

I I. Em torno de 28\% dos alunos nunca lêem livros de não-ficção e I3\% deles lêem esse gênero quase sempre. As obras de não-ficção são lidas por 17\% dos alunos, e os livros de auto-ajuda e esoterismo têm baixa expressão nessa faixa etária.

12. Numa tentativa de categorização, dividimos os livros em quatro gêneros (ficção, não ficção, auto-ajuda e infanto-juvenil), sendo que as obras de ficção são o gênero preferido dos alunos. Nessa categoria incluímos livros que recentemente ocuparam o cume das listas dos mais vendidos, e que foram transformados em superproduções cinematográficas, como O senhor do anéis e a série Harry Potter. Outras obras de ficção citadas pelos alunos são clássicos da literatura brasileira, provavelmente indicados como leitura obrigatória pela escola.

13. Verificamos baixa freqüência aos eventos eruditos (ópera, balé, concertos), visto que a opção "nunca freqüenta" foi assinalada por $74 \%$ dos respondentes. Da mesma forma, as bibliotecas nunca são freqüentadas por mais de $60 \%$ dos jovens. 
atitude provavelmente pode ser explicada pelo aumento de complexidade da vida urbana e pela própria mudança no habitus cultural das frações de elite brasileira, dada a crescente influência das novas tecnologias no cotidiano das famílias e seu impacto na educação de crianças e jovens, instituindo novos padrões de legitimidade que influem no estilo de vida dos jovens investigados.

\section{CLIMA ESCOLAR}

A percepção dos alunos acerca do ambiente escolar, dos professores e do processo de ensino-aprendizagem indica um clima escolar positivo. Os alunos investigados vêem ambas as escolas como um ambiente no qual fazem amigos facilmente $(77 \%)$ e ficam à vontade $(76 \%)$. Sobre o relacionamento entre professores e alunos, cerca de $80 \%$ dos alunos afirmaram que se relacionam bem com os professores, e isso ocorre de forma freqüente ${ }^{14}$. Segundo a percepção dos alunos, essas escolas possuem um corpo docente interessado na sua aprendizagem, pois a maioria dos professores os incentiva a melhorar (60\%), está disponível para esclarecer suas dúvidas (70\%) e dá oportunidades para que expressem suas opiniões ${ }^{15}$ (44\%). Esses dados vêm confirmar as pesquisas sobre o efeito-professor e o efeito-escola que indicam que é possível melhorar as aquisições de um grande número de alunos mediante estratégias adequadas de apoio e incentivo aos jovens (Bressoux, 2003).

As características do corpo docente, por sua vez, evidenciam um grupo de professores bastante experientes, quase todos com mais de 40 anos de idade e mais de 16 anos de formados; muito estáveis nessas escolas (49\% trabalhando no estabelecimento por mais de 16 anos) e que se reconhecem como no ápice da carreira, auferindo os melhores salários da categoria (72\% consideraram seu salário acima da média). O tempo de magistério nessas escolas pode ainda ser inferido como um indicador das boas condições de trabalho oferecidas por essas instituições. Segundo Cousin ( 1998), a estabilidade do corpo docente e da equipe administrativa é uma das pré-condições fundamentais para a construção de "políticas institucionais de sucesso". Cousin (1998) enumera entre

14. Apesar dos $20 \%$ que afirmaram que os alunos raramente se relacionam bem com os professores.

15. Em termos de percepções negativas sobre os professores: $5 \%$ não os incentivam a melhorar, $3 \%$ não estão dispostos a esclarecer dúvidas, $10 \%$ não dão oportunidade para expressarem as suas opiniões. 
outros indicadores importantes para a construção da excelência escolar: sua imagem perante a clientela; a coesão institucional e a adesão do corpo docente ao projeto institucional.

Os dados acerca da percepção da maioria dos alunos, comparados aos descritos no questionário dos pais e professores, evidenciam que há um clima institucional e pedagógico muito bom nessas escolas, confirmando-as como instituições que implementam projetos pedagógicos bem-sucedidos.

\section{A "CIRCULARIDADE VIRTUOSA"}

Nossa pesquisa parte da premissa que escolas de prestígio, como as que estamos estudando, são o locus de escolarização das elites dos diferentes tipos: intelectuais, artísticas, econômicas etc. É nossa suposição que os alunos, mesmo aqueles que procedem de camadas menos providas de capital (econômico, cultural, social etc.), ao se matricularem nessas escolas, estão de alguma forma referidos às elites. Mediante investimentos em estratégias educativas e escolares próprias das elites, as famílias estão simultaneamente apensando capital simbólico às credenciais escolares dos seus filhos e, garantindo uma aproximação social de setores das elites que potencializariam a aquisição de novas formas de capital.

Esses dois tipos de capital - simbólico e social - funcionariam como "curingas" que ampliam as condições de sucesso no jogo social, tornando-se valiosos componentes na estrutura e volume de capital dos agentes. Em contrapartida, cabe destacar que o prestígio dessas escolas foi construído e tende a se reproduzir com base nas características da clientela que consegue atrair. Esse público constitui um grupo que, em face de seu elevado capital escolar, é dotado de recursos críticos, bem acima da média da população brasileira, para monitorar simultaneamente o desempenho dos filhos e dos agentes institucionais que compõem o corpo técnico-administrativo dessas escolas. Dessa forma, no cálculo dos efeitos agregados por tais escolas à sua clientela, em termos de qualidade de ensino, devem estar supostos os efeitos agregados pelo padrão de vida e pelo estilo educativo dessas famílias. Assim, uma "circularidade virtuosa" ${ }^{16}$ se forma quando as condições materiais das instalações dessas es-

16. Essa expressão é criada tomando como referência a noção de "círculo virtuoso" empregado por Maria Alice Nogueira (2000) para caracterizar as trajetórias das escolas particulares/universidades públicas de prestígio próprias das elites. 
colas, o projeto político-pedagógico que implementam e, a qualidade e experiência dos profissionais que elas recrutam vêm garantindo a fidelidade de uma clientela, potencialmente ideal, para reproduzir o selo de excelência acadêmica com que se distinguem no cenário educacional brasileiro.

\section{REFERÊNCIAS BIBLIOGRÁFICAS}

ALMEIDA, A. M. F. de; NOGUEIRA, M. A. (orgs.) A Escolarização das elites. um panorama internacional da pesquisa. Petrópolis: Vozes, 2002.

BRANDÃO, Z;; LELIS, I. Elites acadêmicas e escolarização dos filhos. Educação \& Sociedade. n.83, p. 509-526, ago. 2003.

BOURDIEU, P. La Distinción: criterios y bases sociales del gusto. Madrid: Taurus, 1999.

Escritos de educação. 5.ed. Petrópolis: Vozes, 2003.

Razóes práticas. sobre a teoria da ação. Campinas: Papirus, 1996.

BRESSOUX, P. As Pesquisas sobre o efeito-escola e o efeito-professor. Educação em Revista: Revista da Faculdade de Educação da UFMG. Belo Horizonte, n.38, p. 17-88, dez.2003.

COLEMAN, J. S. Social capital in the creation of human capital. American Journal of Sociology, v.94, p.95-120, 1988.

COUSIN, O. L'Efficacité des collèges. sociologie de l'effet établissement. Paris: PUF, 1998.

DANTAS, M. A Lógica do capital-informação: a fragmentação dos monopólios e a monopolização dos fragmentos num mundo de comunicações globais. Rio de Janeiro: Contraponto, 2002.

FRANCO, C. Educação das elites no Brasil: a Bélgica não existe. Trabalho e Sociedade, Rio de Janeiro, v.2, n.4, p. I3-15, ago. 2002.

LAHIRE, B. Sucesso escolar nos meios populares. as razões do improvável. São Paulo: Ática, 1997. NOGUEIRA, M. A. A Construção da excelência escolar: um estudo de trajetórias feito com estudantes universitários provenientes das camadas médias intelectualizadas. In: NOGUElRA, M.A.; ROMANELLI, G.; ZAGO, N. (orgs.) Familia \& escola: trajetórias de escolarização em camadas médias e populares. Petrópolis: Vozes, 2000.

ROSENTHAL, R. A.; JACOBSON, L. Pigmalion in the classroom: teacher expectations and pupil's intellectual development. New York: Holt, Rinehart and Wisnton, 1968.

Recebido em: outubro 2004

Aprovado para publicação em: maio 2005 